MODELING, IDENTIFICATION AND CONTROL, 1980, vOL. 1, NO. 2, 67-68

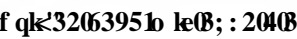

\title{
Modeling and identification of marine ecological systems with applications in management of fish resources and planning of fisheries operations
}

\author{
JENS G. BALCHEN†
}

During the past decade, there has been an increasing interest in Norway in applying the methods of mathematical/numerical modeling, identification and control to individual processes and to the complex of interacting phenomena in the marine ecological system. Since Norway has close access to some of the world's richest fishing grounds, the fishing industry plays an important role not only in the nation's economy, but it also has a strong influence upon the daily life in large areas of the country. Whereas the most important problem some decades ago was to develop more efficient harvesting techniques, a dominating problem in more recent times has become that of estimating the resources of fish and managing the utilization of these resources.

Sponsored by the Royal Norwegian Council for Scientific and Industrial Research and the Norwegian Fisheries Research Council, a long range research and development program was started around 1974 under the title HAVBIOMODELLER (English translation OCEAN BIO-MODELS) (Balchen 1979). The goal of this program is to establish the capability of producing mathematical/numerical models of a total marine ecological system of the Barents Sea, north of Norway. The total ecological system of the Barents Sea is modeled by a set of submodels describing:

(1) The subsystem of physical oceanography (water velocity, turbulence, temperature, salinity).

(2) The subsystem of chemical oceanography and phytoplankton (concentration of nutrients, concentration and distribution of some classes of phytoplankton).

(3) The subsystem of zooplankton (physiological states, behavior, population of most important species).

(4) The subsystem of fish (physiological states, behavior, population of most important species).

In addition to formulating the structure of the mathematical models, choosing and testing adequate numerical techniques and writing the computer programs, it is of utmost importance to develop methods for updating the model variables and parameters against actual measurement information obtained from different devices in the ocean. The most powerful techniques known in the fields of state and parameter estimation are adopted for this type of problem and new techniques are developed for generating proper boundary conditions on the open boundaries.

An operational set of models is planned to be available around 1985. The most obvious applications of this system will be in estimating present and future states of the system, particularly those representing the quality, quantity and distribution of the most important species of commercial fish. It is expected, however, that the system

$\uparrow$ The Norwegian Institute of Technology, Division of Engineering Cybernetics, N-7034 Trondheim, Norway.

M.I.C. 
will also have important applications in oceanographic and biological research and in studies of ocean pollution as a consequence of offshore oil activities.

Contributions to this research program are given by a number of Norwegian research institutions and universities. The primary contributors are the Foundation of Scientific and Industrial Research and the Division of Engineering Cybernetics at the Norwegian Institute of Technology, Trondheim and the Institute of Marine Research, Bergen. The program is headed by Professor Jens G. Balchen, Trondheim.

Starting in this issue, MIC will present a number of papers giving details about the above research program. It has been decided that these papers shall not be presented in any systematic order, but proper reference is given in each paper to the research program HAVBIOMODELLER (OCEAN BIO-MODELS).

In this issue, a paper is presented by Professor Wolfgang Ebenhöh from the University of Oldenburg, Germany who has been associated with the above research program in Trondheim, under a three months leave of absence from Germany. The title of his paper is 'A Model of the Dynamics of Plankton Patchiness'.

\section{REFERENCE}

BALCHEN, J. G. (1979). Mathematical and numerical modeling of physical and biological processes in the Barents Sea. Statistical Ecology Series, Gen. Ed. G. P. Patil, No. 13, Quantitative Population Dynamics, International Cooperative Publishing House, P.O. Box 245, Burtonsville, MD, 20730, U.S.A. 